Apoio Cultural 


\section{Prêmio Moinho Santista: tradição a serviço da inteligência nacional}

\section{RUY MARTINS ALTENFELDER SILVA}

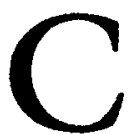

riadas para servir, as fundaçōes atuam como poderoso instrumento de desenvolvimento científico, tecnológico e social. Suportes para organismos governamentais, em geral limitados pela exigüidade de recursos, as fundaçóes tornaram-se indispensáveis agentes de promoçáo do homem e de suas idéias. É assim em todo o mundo e, especialmente, no Brasil. Um bom exemplo é a Fundaçáo Moinho Santista, que há $\mathbf{3 9}$ anos estimula a produçăo intelectual, ajudando a construir o progresso do país.

A Fundaçăo Moinho Santista nasceu em 1955, com a proposta de projetar grandes nomes das Ciências, Letras e Artes em âmbito nacional. Comemorava-se à época o 50\% aniversário da S.A. Moinho Santista Indústrias Gerais e a forma escolhida para aproximar a empresa da comunidade foi a instituiçăo de um prêmio anual.

O objetivo tem sido alcançado e ampliado a cada ano. O Prêmio Moinho Santista e o Prêmio Moinho Santista Juventude - este criado em 1980 - são qualitativamente considerados os melhores do país em função de seu pioneirismo, rigor nos critérios de avaliaçáo e escolha dos candidatos, reconhecimento, repercussáo e por não terem sofrido interrupçáo uma vez sequer. São também os maiores, pelo valor venal, $R S$ 100 mil, além de diplomas e medalhas de ouro e prata.

Nesses quase $\mathbf{4 0}$ anos, houve aperfeiçoamento da premiação, de forma que ninguém interfere em seu mecanismo. Podemos citar três de suas características: primeira, não há inscrição; segunda, as entidades que indicam os candidatos têm reconhecimento nacional; e, terceira, absoluto sigilo, tanto que só se fica sabendo quem sáo os vencedores, năo os vencidos.

A iniciativa da Fundação Moinho Santista hoje tem repercussão internacional e náo sofre intervençóes de qualquer ordem. Os premiados são escolhidos única e exclusivamente por seu valor, pela contribuiçáo de suas obras, como atestam as homenagens prestadas ao pesquisador 
Carlos Chagas Filho, ao sociólogo Gilberto Freyre, ao filósofo e jurista Miguel Reale, ao escritor Jorge Amado, aos poetas Menotti Del Picchia e Manuel Bandeira, ao ator Paulo Autran e a tantas outras personalidades.

Seis áreas do conhecimento humano, determinadas conforme classificação do Conselho Federal de Educaçáo, alternam-se a cada ano: Ciências Biológicas e Profissionais da Saúde; Ciências Exatas e Tecnológicas; Ciências Agrárias; Ciências Humanas e Sociais; Letras; e Artes.

Para cada área, são escolhidos dois ramos de premiaçăo, durante reuniáo do Conselho da Fundação, em dezembro do ano anterior. Seis meses depois, a Comissão Técnica - órgáo estatutário - escolhe os vencedores da categoria Juventude e seleciona quatro finalistas do Prêmio Moinho Santista, dos quais dois saem vencedores, apontados pelo Grande Júri, que sempre se reúne em agosto, no salâo nobre do Tribunal de Justiça do Estado de São Paulo.

\section{Os vitoriosos de 1994}

Este ano, o Prêmio Moinho Santista enfocou as Ciências Agrárias em seus ramos de Engenharia Florestal e Solos Agrícolas. Retomaremos esse tema no ano 2000 e em 1995 a área será a de Ciências Humanas e Sociais.

Como ocorre há quatro décadas, a 30 de setembro, dia do 89 을 aniversário da S.A. Moinho Santista Indústrias Gerais, o governador do estado, presidente honorário da Fundação, conduziu a cerimônia de premiação, no Palácio dos Bandeirantes, homenageando quatro destacados nomes em Ciências Agrárias. Os dois vencedores do Prêmio Moinho Santista foram Luiz Ernesto George Barrichelo, no ramo de Engenharia Florestal, e Marcelo Nunes Camargo, em Solos Agrícolas. $\mathrm{Na}$ categoria Juventude, saíram vitoriosos Margarete Marin Lordelo Volpato e Gerd Sparovek.

Os currículos desses quatro pesquisadores atestam o acerto da escolha, feita por representantes da comunidade acadêmica e de instituiçóes científicas. Barrichelo, por exemplo, é um especialista em eucalipto e sua utilização na produção de papel e celulose. Engenheiro agrônomo graduado pela Escola Superior de Agricultura "Luiz de Queiroz" da USP, em Piracicaba, ali recebeu, cinco anos depois, o título de doutor. Nessa instituiçáo, divide-se entre seus estudos, reconhecidos mundialmente, e a missão de formar, como professor titular do Departamento de Ciências Florestais.

Outro homenageado, Marcelo Nunes Camargo, formou-se en- 


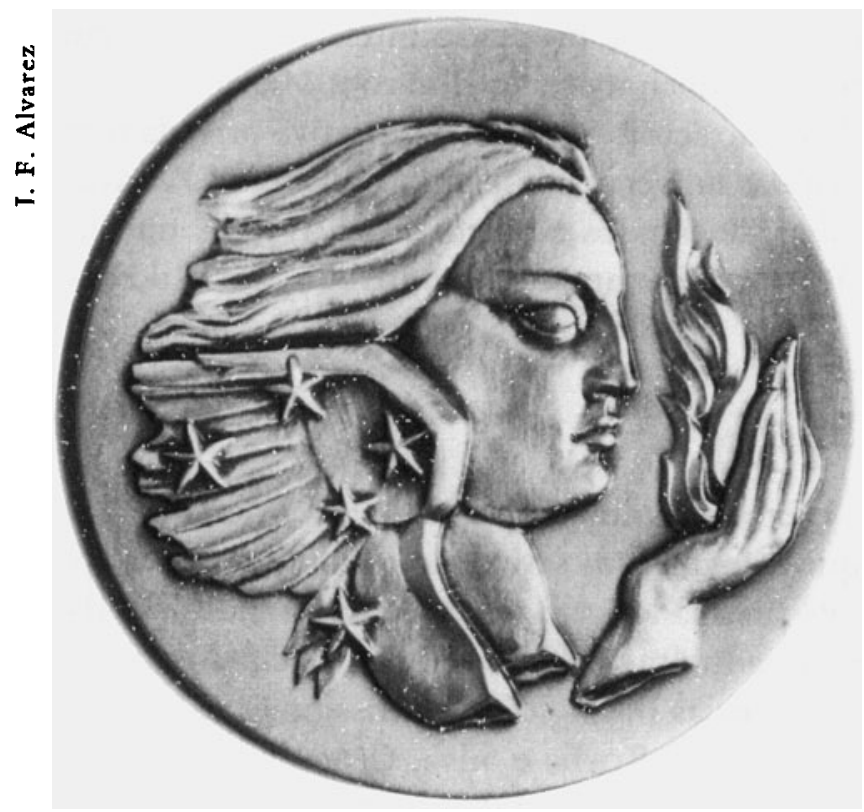

Efige da medalha entregue aos vencedores do Prêmio Moinho Santista

genheiro agrônomo pela Universidade Rural do Brasil, atual Universidade Federal Rural do Rio de Janeiro. É autor do Sistema de Classificaçáo de Solos do Brasil e coordenou a elaboração do primeiro Mapa de Solos do país, em trabalho inédito que tem auxiliado significativamente nos julgamentos de aptidão agrícola nas diversas regioóes do país.

Enquanto o Prêmio Moinho Santista é concedido tomando-se por base vida e obra do candidato, a premiação para o segmento Juventude leva em conta dissertaçóes de mestrado ou teses de doutorado e impóe limite de idade: até 35 anos. Gerd Sparovek, 32 anos, doutor em Solos e Nutriçáo de Plantas pela Escola Superior de Agricultura "Luiz de Queiroz" da USP, destacou-se pela Amostragem e análise de dados edafobio-climáticos de um remanescente florestal no municipio de Pindorama-SP. Sua pesquisa contribui para melhorar os métodos de amostragem de solos em florestas tropicais.

Margarete Marin Lordelo Volpato, 28, é autora de brilhante tese, apresentada ao concluir o curso de mestrado na Universidade Federal de Viçosa-MG sob o título de Regeneraf̧ão natural em uma floresta secundária no dominio de mata atlantica: uma análise fitossociológica. Para provar que a recuperação da floresta é possível, Margarete estudou mais de 2.800 plantas de 95 espécies e 34 famílias.

A Fundaçáo Moinho Santista cumpre seu objetivo, mais uma vez, mostrando à sociedade a importância da pesquisa. O estudo vale a pena, 
mesmo em um país onde o incentivo à produção intelectual, por parte de órgãos governamentais, é tão incipiente. As dotaçóes oficiais sáo mínimas diante das necessidades do setor. Por isso, a iniciativa privada tem a obrigação de se aproximar das universidades, não só celebrando convênios, mas concedendo bolsas de estudos e outros incentivos. É um investimento que retorna às próprias empresas e contribui para o desenvolvimento do país.

\section{Presença da USP}

O prêmio tem sido oferecido ininterruptamente e a galeria de homenageados comprova que se agiu com seriedade e justiça. Nesses 39 anos, por exemplo, entre 94 premiados, um terço recebeu a indicaçáo da Universidade de Sáo Paulo, indubitavelmente um dos celeiros da intelectualidade brasileira. Em Ciências Biológicas e Profissionais da Saúde, tivemos os professores Maurício da Rocha e Silva, Crodowaldo Pavan, Luiz Décourt, Diogo Pupo Nogueira, Euryclides de Jesus Zerbini e José Galízia Tundisi.

Em Ciências Exatas e Tecnológicas, foram homenageados os professores Jorge André Swieca, César Lattes, Oscar Sala, Fausto Walter de Lima, Giuseppe Cilento, Paschoal Senise, Walter Borzani, Eduardo Rottmann e Newton Affonso da Costa. Outros quatro professores já receberam prêmios na área de Ciências Agrárias: Eurípedes Malavolta, Fernando Homem de Mello, Adriano Júlio de Azevedo Filho e Maria Gabriela Guimarães Ribeiro dos Santos. Além dos dois escolhidos este ano, Luiz Barrichelo e Gerd Sparovek.

Integram a galeria, em Ciências Humanas e Sociais, os professores Waldemar Martins Ferreira, Miguel Reale, Goffredo da Silva Telles Junior, Vicente Ferreira da Silva, Alexandre Corrêa, Antônio Ferreira de Almeida Junior, Fernando de Azevedo, Nicolau Sevcenko e Jacques Marcovitch. E, finalmente, a USP marca sua valiosa participação na área de Letras, com os professores Antônio Cândido de Mello e Souza e Margaret de Miranda Rosa.

\section{Consagração da inteligência}

Todos os premiados são exemplos de integração da intelectualidade brasileira, que a Fundação faz questão de reunir, anualmente, no Palácio dos Bandeirantes, casa do presidente honorário, o governador do estado. Ali fazemos a festa da inteligência, o maior produto do Prêmio. É o momento em que os valores intelectuais sobrepöem-se aos materiais. 
À Fundação Moinho Santista também cabe um prêmio: o de ver sua iniciativa abrir novas portas ao homenageado $\mathrm{e}$, não raro, ao país. Recentemente, tivemos mostra disso, ao receber carta de Ricardo Câmara Leal, premiado na categoria Juventude, em 1989, na área de Administraçăo de Empresas. Desde 1992 ele é professor na Universidade de Georgetown, em Washington, uma das instituiçóes acadêmicas de maior prestígio nos Estados Unidos.

Convidado para congressos no mundo inteiro, por suas pesquisas sobre abertura de capital nos Estados Unidos e na Alemanha e sobre mercados emergentes de açóes na Àsia e América Latina, Ricardo Câmara Leal deu-nos estimulante depoimento: "O prêmio que recebi foi um grande incentivo para uma carreira acadêmica bem-sucedida até agora". Atitudes como essa dão à Fundação a certeza do caminho certo.

Ruy Martins Altenfelder Silva é conselheiro e coordenador das atividades da Fundaçăo Moinho Santista. 